\title{
16 Health savings accounts in the United States of America
}

\author{
SHERRY A. GLIED, DAN P. LY AND LAWRENCE D. \\ BROWN
}

The medical savings account model of health insurance in the United States combines a high-deductible health insurance plan ${ }^{1}$ with a dedicated savings account used to pay expenses incurred below the deductible. Savings in the plan can roll over from one year to the next and, after some predefined period during which they are dedicated to health spending, can be used for non-health-related expenses. ${ }^{2}$ In principle, this model combines the incentives for frugal use of health services that exist in high-deductible health insurance with assurance that the funds required in the event of true medical need will be available.

In the United States, interest in and experimentation with this model began, on a very small scale, in the mid-1970s. Beginning in 1996, the use of this model in private, voluntary health insurance in the United States was promoted through a series of tax incentives. The first of these incentives, a limited demonstration project (capped at a maximum of 750000 enrollees), was passed as part of the Health Insurance Portability and Accountability Act of 1996, which allowed self-employed individuals and businesses with fewer than 50 employees who were covered under qualified high-deductible health plans to make tax-exempt contributions to medical savings accounts.

When the demonstration project ended enrolment in 2000, about 100000 individuals had signed up. Next, in 2002, the Treasury Department, which directs the Internal Revenue Service, issued a notice indicating that an employer's contribution to an account set aside for

${ }^{1}$ A high-deductible health plan is an insurance plan under which the beneficiary is responsible for a substantial amount of expense (the deductible) before the insurer begins paying benefits. US federal law as of 2015 requires a deductible of at least US\$1300 for single coverage and US\$2600 for family coverage for health saving account-qualified high-deductible health plans (Dolan, 2016).

${ }^{2}$ Use of savings for non-health expenses before this predefined period (age 65 under current law), incurs a tax and $20 \%$ penalty. 
health care is not taxable income to the employee and that any unused funds in such an account can be rolled forward from year to year (Newhouse, 2004). The resulting Health Reimbursement Accounts can be, but need not be - and often are not - coupled with high-deductible health plans. Health Reimbursement Accounts are similar to Health Savings Account, but are funded entirely by employers and are generally not portable between jobs. ${ }^{3}$

The following year, Title XII of the 2003 Medicare Prescription Drug, Improvement and Modernization Act provided a tax incentive for the establishment of Health Savings Accounts (HSAs) coupled with qualified high-deductible health plans. Under this legislation, contributions to HSAs are tax exempt, as is interest on savings that accumulate within HSAs, and disbursements from HSAs are also tax exempt if they are used for qualified medical expenses (Grudzien, 2006). HSA plans are owned by the insured individual and can be transferred from one job to another. The provisions governing HSAs were made somewhat more generous under the Tax Relief and Health Care Act of 2006. The Affordable Care Act enacted in 2010 set binding minimum medical loss ratios (percentage of premiums spent on health care claims and quality-improving expenses) for all plans, including HSA-qualified high-deductible health plans. The reform also raised the penalty for premature withdrawals from HSAs, limited their use in paying for over-the-counter pharmaceuticals, and required all plans, including HSA-qualified plans, to cover a set of preventive services without cost sharing (so making them exempt from the deductible) (Kaiser Family Foundation, 2013; Dolan, 2016).

In addition to these tax incentives, which apply to the private health insurance market, the medical savings account model has been incorporated into public health insurance programmes - Medicaid and Medicare (see Chapter 15 in this volume). Medicaid, which is funded jointly by the federal and state governments and operates under state jurisdiction in compliance with federal regulations, serves low-income

${ }^{3}$ Health Reimbursement Accounts (HRAs) are funded and owned by employers. Because of this, when an employee with an HRA changes or loses his or her job, the remaining amount in the HRA defaults to the employer. Health Savings Accounts (HSAs) may be funded by both employers and employees. As a result, an employee may take unused amounts with him or her when changing jobs. More firms offer HSAs than HRAs (Kaiser Family Foundation, 2015). 
Americans who meet various categorical eligibility criteria. Before the Affordable Care Act, several states had incorporated health savings accounts into their Medicaid programme (Andrews, 2014). Two states currently have waivers allowing them to incorporate HSA-like features in their Medicaid expansions for people with incomes between $100 \%$ and $138 \%$ of the Federal Poverty Level (Musumeci \& Rudowitz, 2015).

Medicare is a federal programme that provides health insurance to older (aged 65 years and over) and disabled Americans, regardless of income. The Centers for Medicare and Medicaid Services is the federal agency that operates the traditional Medicare health insurance programme and also subcontracts with private insurers to offer a variety of alternative plans. Medicare beneficiaries can select medical savings account model plans as an alternative to traditional Medicare (Centers for Medicare and Medicaid Services, 2012). The plans involve a highdeductible insurance product and a savings account, into which Centers for Medicare and Medicaid Services will make an annual lump-sum deposit. Funds will be tax exempt as long as they are used to pay for qualified medical expenses.

These policy initiatives have generated considerable interest. In 2014, about 35 million Americans were enrolled in health insurance plans with deductibles above the HSA threshold (see footnote 285). Of these, just over a third had an HSA (Cohen \& Martinez, 2015). In this chapter, we review the history and motivation behind the introduction of HSAs. We then describe the regulation of the HSA market, the structure of this market and its performance to date. We conclude by discussing the implications of HSAs for the US health insurance system.

\section{History and current status}

The adoption of public policies promoting the use of medical savings accounts in the United States occurred through the confluence of three distinct developments: a line of academic research; a set of entrepreneurial lobbying and marketing efforts; and a market vacuum.

\section{Academic research}

Beginning in the late 1960s, academic economists turned their attention to the structure of prevailing voluntary health insurance plans. Economic theory suggested that the plans that were most frequently 
selected were excessively generous in their cost-sharing requirements and benefits and, correspondingly, charged excessively costly premiums (Pauly, 1968; Feldstein, 1973). The logic of this argument was based on a general theoretical point in conjunction with observation of the marketplace. Economic theory suggests that, given the choice between the cash value of medical services and the medical services themselves, many people would prefer the cash. However, under health insurance, which effectively subsidizes the cost of medical services to the consumer, they would tend to use the medical services. Moreover, in a purely private and voluntary market, they would pay for these low (subjective) value services through their premiums, leaving them with less cash and more low subjective value medical services than they would prefer. The RAND experiment, conducted in the late 1970s and early 1980s, provided empirical confirmation of the expected theoretical result, showing that people who faced higher cost sharing used fewer medical services, even though they were compensated by the study sponsors for the higher out-of-pocket costs by lump-sum cash transfers (Newhouse, 2004).

This excess medical service use induced by the presence of insurance, or so-called moral hazard, which diminishes individual welfare, is the inevitable consequence of the economically valuable risk reduction implicit in health insurance (Feldstein, 2006). Thus, the existence of moral hazard, alone, called for no particular policy response. In a series of simulation studies based on estimates of willingness to pay to avoid risk, however, several economists concluded that the most common voluntarily selected insurance plans generated much more welfare loss in the form of moral hazard than the gains in welfare that they induced through reduced risk bearing. The prevailing plans appeared to be economically inefficient choices (Feldman \& Dowd, 1991; Manning \& Marquis, 1996).

Economists concluded that the leading factor inducing these apparently inefficient choices was the favourable tax treatment of employersponsored health insurance. At the time of the introduction of private employer-sponsored health insurance, in the early 1930s, the tax authorities had, in practice, ignored the value of employer insurance payments on behalf of employees in computing income taxes owed. This practice was ratified in the 1954 Internal Revenue Code that formally exempted employer contributions to insurance plans from income taxation (Blumenthal, 2006). Employer contributions for health insurance are also exempt from Medicare and Social Security payroll taxation 
and, in general, from state income taxes. In effect, these exemptions can generate a subsidy of over $40 \%$ (for high-income workers who face high marginal tax rates) toward health insurance premiums.

The effect of this substantial subsidy, economists argue, is to induce people, especially those with higher incomes, to choose health insurance plans with higher than optimal premiums (because the premiums are so heavily subsidized) and correspondingly lower cost sharing (because payments made for cost sharing are not subsidized at all) (Pauly, 1986). These generous health insurance plans then induce the excess use of medical services. A public policy - the tax treatment of health insurance - can explain the apparently irrational health insurance choices prevailing in the private market.

The obvious policy response to this argument would be to withdraw the favourable tax treatment of employer-sponsored coverage. Although the economic logic for such a move is impeccable, and withdrawing the subsidy would be progressive over much of the population, it is politically challenging. ${ }^{4}$ Instead, advocates sought a policy that would undo the effects of the tax treatment without withdrawing the tax treatment itself. One such option is to extend the favourable tax treatment to include not only premiums, but also out-of-pocket payments made to cover coinsurance and deductibles. The effect of this further tax exemption would be to neutralize the distortion between premiums and cost sharing induced by the existing tax treatment and lead people to choose less generous health insurance policies (Jack \& Sheiner, 1997; Cogan, Hubbard \& Kessler, 2005). Medical savings accounts, which provide a tax exemption to funds saved for cost sharing and other medical expenses, offer one vehicle for providing this additional, off-setting tax subsidy (Bunce, 2001).

\section{Entrepreneurial lobbying}

The academic research arguing that conventional health insurance plans led to welfare losses spurred the development of insurance plans that

${ }^{4}$ The recent health care reform law included a provision that would, starting in 2018 , implement a $40 \%$ excise tax on plans with annual premiums over a certain amount. The tax would apply to the portion exceeding this amount, and it would not be deductible. The provision has been delayed until 2020 and there have been sustained efforts to repeal it. 
would not have these negative effects. The first of these options, the so-called health bank, was proposed in the mid-1970s by economists Jesse Hixson and Paul Worthington, working in the Social Security Administration (Hixson \& Worthington, 1978). Under this proposal, employers would deposit money for health care directly into the savings accounts of employees and employees could draw on these accounts to pay for routine expenses. In 1979, the Office of Education in Mendocino County adopted a stay-well plan in which employees' first-dollar coverage plan was replaced with a US $\$ 500$ deductible policy from the same insurer, and the annual premium savings of about US $\$ 480$ per worker were used to establish a side fund. Unused balances remaining in the side fund would be remitted to the employee when he or she quit or retired (Heffley \& Miceli, 1998; Bogetic \& Heffley, 2007).

In the early 1980 s, conservative think-tanks began to popularize the health bank idea, and developed the notion of a medical savings account (Bunce, 2001). The chair of one small insurance company, Golden Rule Insurance, decided to move ahead with the idea, offering a combination high-deductible and savings plan initially to his own employees and, later, more broadly (Bunce, 2001). The market for this coverage was small, however, and proponents and promoters of the plan argued that the lack of interest could be attributed to the existing tax subsidy.

During the 1990s, opponents of the tax subsidy and a coalition of small insurers, led by Golden Rule, lobbied very aggressively for changes in the tax code that would promote the development of medical savings accounts (Dreyfuss \& Stone, 1996; Pear, 1996). Their efforts were successful in achieving passage of the medical savings account demonstration project as part of the 1996 Health Insurance Accountability and Portability Act legislation, and then in the inclusion of the HSA provisions in the Medicare Modernization Act (2003).

\section{Market vacuum}

The third impetus for the introduction of HSAs was growing disenchantment with managed care (see Chapter 15 in this volume). Enrolment in managed care plans had soared during the 1990s and, between 1993 and 1999, this form of insurance slowed the growth of costs quite effectively (Glied, 2003a; Gratzer, 2005). Cost containment in managed care, however, came at the expense of patient and provider autonomy (Blendon et al., 1998). In the latter half of the 1990s, critical media 
coverage, provider resistance, negative legal decisions, and legislation in the states to protect subscribers and providers ate away at the ability of managed care plans to control costs (Bloche \& Studdert, 2004; Brodie, Brady \& Altman, 1997). By the end of the decade, health care cost growth had returned to customary levels, and managed care was becoming increasingly unpopular.

In this environment, employers (who make most private health insurance purchasing decisions in the United States), the brokers, agents and consultants who advised them and the insurers selling plans, all sought an alternative cost containment option. In response, market proponents advocated a model of consumer-driven health care (Reinhardt, 1998). The consumer-driven model, promulgated by a group of new technology-savvy insurance companies funded through venture capital, was designed to exploit new information and communications technologies so as to provide patients with information and decision tools, allowing them to weigh the costs and quality of the care they chose. Implicit in this model was the use of a high-deductible health plan and a related medical savings account.

High-deductible health plans had always been available, but the combination of these innovative information tools and the HSA tax subsidy made them a more attractive choice for employers. The lack of an attractive managed care-style alternative further cemented their appeal. By the early 2000s, consumer-directed health plans were a highly prominent focus of health insurance industry marketing attention.

\section{Current status}

As the discussion above suggests, the public policy treatment of the medical savings account model continues to evolve. For the private sector, policy-makers have promoted the model exclusively through a tax subsidy to savings accounts held in combination with qualified high-deductible health plans. The current (2016) tax subsidy, provided through the provisions of the 2003 Medicare Modernization Act, offers three benefits to holding an HSA. First, money contributed to the account by individuals or by employers on their behalf is not subject to tax; individual buyers, including the self-employed, may deduct these contributions from their taxable income; and employer contributions are excludable from income and wage taxes. Second, money can accumulate interest in the account tax-free and may be invested at the 
account holder's discretion. Lastly, the money may be used tax-free for qualified medical expenses (other than insurance premiums). Spending on things other than qualified medical expenses can be included in an individual's gross income and is subject to an additional $20 \%$ tax penalty (Grudzien, 2006; Dolan, 2016).

Under existing law, a person may only make contributions to an HSA as long as he or she is covered by a qualified high-deductible health plan. A health plan qualifies under this law if the annual deductible is not less than US $\$ 1300$ for individuals or US $\$ 2600$ for family coverage, and the maximum out-of-pocket $\operatorname{costs}^{5}$ do not exceed US\$6550 for individuals and US\$13 100 for families (Dolan, 2016). Most Affordable Care Act-compliant bronze level plans sold in the marketplaces could, therefore, be paired with an HSA, though in practice, few such plans are sold in combination with savings accounts (Federal Register, 2016).

The maximum annual contribution to an HSA is also defined in law. For 2017, individuals may make contributions of up to US\$3400 for individuals and US\$6750 for families (Internal Revenue Service, 2016). Contributions to HSAs may be made by individuals or by employers on their behalf. The account, however, belongs to the individual, and all contributions, whatever their source, remain in the ownership and control of the individual. Payments for premiums for high-deductible plans made in conjunction with HSAs are subject to the same tax rules that govern other insurance plans. For employed people, employer contributions toward premiums are excludable from taxable income. For self-employed people, premium payments are deductible from taxable income.

Lower-income people who purchase health insurance in the Affordable Care Act marketplaces may receive subsidies toward their premiums. Those who purchase nongroup coverage through the exchanges have access to two types of subsidies: premium tax credits, which reduce monthly payments for insurance coverage, and cost-sharing subsidies, which reduce enrollees' out-of-pocket costs for medical care. Enrollees are eligible for premium tax credits if their income is between $100 \%$ and $400 \%$ of the federal poverty level; they do not have access to affordable coverage through an employer; and they are not eligible for public assistance programmes like Medicare, Medicaid, or the Children's

${ }^{5}$ Out-of-pocket costs include the deductible and other forms of cost sharing but not premiums. 
Health Insurance Program. They are eligible for a cost-sharing subsidy if they purchase a silver plan; meet all criteria for receiving a premium tax credit; and have household incomes between $100 \%$ and $250 \%$ of the federal poverty level (Kaiser Family Foundation, 2013). People with incomes above the subsidy level, who do not obtain coverage through an employer receive no tax advantages - they must pay for premiums from after-tax income.

\section{Regulation of medical savings account model plans}

The federal legislation that enabled the creation of tax-exempt HSAs regulates only the deductible and out-of-pocket maximum requirements of the corresponding high-deductible health plans. Other tax-related regulations governing HSAs and other employer-provided benefit programmes focus on ensuring that benefit plans are not used to shield highly compensated employees from taxation.

At the federal level, the Internal Revenue Service requires that employers make "comparable contributions" under benefit plans for all "comparable participating employees". This requirement implies that employers must make the same contribution to the accounts of all employees who select the same type of plan (Moran \& Farmer, 2007). In the HSA context, this comparability requirement has been modified to permit employers to make larger HSA contributions on behalf of non-highly compensated employees (those in the lower $80 \%$ of the compensation distribution within the firm; Joint Committee on Taxation, 2006; Internal Revenue Service, 2017). Both the favourable tax treatment of HSAs (which varies positively with marginal tax rates) and the tax-free savings component of these plans make them inherently more attractive to higher-paid employees. This provision allows employers to sweeten an HSA-qualified plan for lower-paid employees by making larger contributions into their accounts.

States also have the option of extending their own tax preferences toward HSAs. Twenty-seven states use the federal definition of taxable income and therefore recognize all deductions and exclusions under federal law for state income tax filers, while another nine states do not have a state income tax. The remainder of the states, however, need a specific law singling out HSAs for favourable tax treatment and, although many have passed such laws, several have not. Many of the states that have not given HSAs tax subsidies have done so because of 
budgetary concerns, whereas others question HSAs on policy grounds (Jost \& Hall, 2006).

The substantive regulation of private insurance largely falls under the authority of the 50 states. The law authorizing HSAs requires nothing of health insurers or the states and it does not free insurers from any existing state requirements (Jost \& Hall, 2006). The law does not compel states to require insurers to offer such policies nor does it force states to allow policies conforming to HSA requirements to be sold.

In practice, although most states quickly paved the way for the establishment of HSA-compatible plans, some did not. At the time that the HSA law was passed, several states mandated coverage of specific nonpreventive services with no or a low deductible. These mandates would disqualify any plan in that state from being HSA-qualified. For example, Florida had a law prohibiting insurers from charging insurance deductibles or co-payments to victims of violent crime while Maryland and Pennsylvania prohibited the application of a deductible for certain home health visits for recently delivered mothers and newborns (Jost $\&$ Hall, 2006). HSA compliant plans are now offered in all 50 states.

Finally, about $80 \%$ of employers with 500 or more employees, and about a third of all employers, currently offer at least one self-insured health plan - plans where the employer, rather than an insurance company, bears the risk of medical expenses (Agency for Healthcare Research and Quality, 2015). These may include HSA-qualified plans. Under the provisions of the federal Employee Retirement Income Security Act (ERISA), these self-insured plans are exempt from all state insurance regulation (and, hence, from virtually all substantive insurance regulation). ERISA does impose fiduciary responsibility on employers, however, and, in the context of HSAs, would make an employer responsible for monitoring the investment performance of such accounts (Moran \& Farmer, 2007). Perhaps to encourage employer funding of HSAs without subjecting them to state regulation, the Labor Department, in Field Assistance Bulletin 2004-1, declared that an employer would not ordinarily become subject to ERISA's fiduciary requirements if it made contributions to an HSA established or maintained by a third party (see Chapter 15 in this volume; Moran \& Farmer, 2007). The provisions of the Affordable Care Act enacted in 2010 do not apply to self-insured plans, so ERISA remains the major piece of federal legislation directly affecting HSA-qualified self-insured plans to date (Jost \& Hall, 2012). 
As noted at the beginning of this chapter, federal regulation of nonself-insured, HSA-qualified plans increased with the passage of the Affordable Care Act, enacted in 2010. That law set binding minimum medical loss ratios (which limit the allowable share of premiums spent on health care claims and quality-improving expenses) for all plans, including HSA-qualified high-deductible health plans; raised the penalty for premature withdrawals from HSAs; limited their use in paying for over-the-counter pharmaceuticals; and required all plans, including HSA-qualified plans, to cover a set of preventive services without cost sharing (which includes deductibles) (Kaiser Family Foundation, 2013; Dolan, 2016). It also required that all health plans pay at least $60 \%$ of the actuarial value of covered benefits. A plan with a $60 \%$ actuarial value is a bronze plan on the Affordable Care Act marketplace.

\section{The health savings account market}

The market for health plans sold in conjunction with medical savings accounts has matured in the United States. Nonetheless, several issues remain.

\section{Forms of medical savings account plans}

The impetus for the development of the medical savings account model has been to allow the market to develop insurance designs that best meet consumer preferences regarding choice, quality and cost. This broad goal meshes uneasily with the need to define the characteristics of plans that will be eligible for tax subsidies (Cannon, 2006).

Regulations interpreting the 2003 HSA legislation permitted some forms of plan design and prohibited others. One important design feature that was permitted is the exemption of preventive health care services from the plan deductible. A series of guidelines issued by the Internal Revenue Service progressively expanded the scope of preventive services exempted. Initially, preventive care was defined to include periodic health evaluations (as well as the tests and procedures used for these evaluations), well-baby and child care, immunizations, tobacco cessation, weight-loss programmes for obesity and certain screenings (Moran $\&$ Farmer, 2007). Subsequently, certain additional procedures, such as the removal of polyps during a diagnostic colonoscopy, performed in conjunction with preventive care, were declared as exempt from the 
deductible requirement (Dotson 2006a). The exemption for preventive care was further extended to include prescription medications provided to prevent the development of a disease in a person who has risk factors for that illness, or to prevent recurrence of a disease (Dotson, 2006b). Two examples given by the Internal Revenue Service were the treatment of high cholesterol with cholesterol-lowering drugs (for example, statins) to prevent heart disease and the treatment of recovered heart attack or stroke victims with angiotensin-converting enzyme inhibitors to prevent a recurrence (Dotson, 2006a).

Insurers took advantage of these provisions by offering HSA-qualified plans that exempt preventive screening. As of 2006 , over $80 \%$ of workers enrolled in HSA-qualified high-deductible plans were enrolled in ones that did not apply the deductible to preventive benefits (Claxton et al., 2006). At least one major insurer, Aetna, also made several drugs eligible for first-dollar coverage (including anti-hypertensives, anti-diabetic agents, lipid-lowering agents, medications for asthma and osteoporosis, and prenatal and childhood vitamins), within its HSA-qualified highdeductible plan (Robinson, 2005). As noted above, the ACA health care reform law has since standardized preventive care coverage, requiring all plans, included HSA-qualified high-deductible health plans, to cover these preventive services free of cost sharing (Kaiser Family Foundation, 2013; Dolan, 2016).

The exemption of preventive care from deductibles makes eminent sense from a health care delivery perspective - but very little sense in terms of the conventional theory of optimal insurance provision. In theory, insurance, which loads an administrative cost on all covered expenses, should cover unanticipated, catastrophic events - not predictable, more affordable, expenses such as preventive services. The market success of high-deductible health plans that provide first-dollar coverage for preventive care suggests that consumers view health care coverage differently from what basic insurance theory predicts.

A second, unanticipated innovation in HSA-qualified plan design has been the fusion of high-deductible plans with elements of managed care. Several insurers have combined high-deductible plans with preferred-provider arrangements (Scheffler \& Felton, 2006). Under these arrangements, the insurer contracts with selected providers to obtain favourable rates for care. The cost of services purchased from in-network providers is then set against the plan's in-network deductible (which must conform to the qualified-plan minima). The cost of services purchased 
from noncontracted, out-of-network providers are applied to a higher, out-of-network deductible. Federal regulations permit the out-of-pocket limit in the HSA law to be exceeded for these out-of-network services (Moran \& Farmer, 2007). These preferred-provider high-deductible plans place limits on the patient's choice of provider - the types of limits that led to concerns about constrained choice under managed care. For many people, however, the advantages of improved bargaining power and price information generated through insurer contracting appear to outweigh these constraints (Hall \& Havighurst, 2005).

Some insurance plans have combined other elements of managed care with HSA-qualified plans. For example, Kaiser Permanente, a large, non-profit, group-model health maintenance organization, which provides fully integrated coverage that includes its own hospitals and exclusively contracted clinics, offers an HSA-qualified plan that restricts participants to the services offered by the health maintenance organization (Kaiser Permanente, 2004, 2016). It is likely to be more difficult to integrate high-deductible provisions with capitation payment or pay-for-performance arrangements that do not pay physicians for each service or visit. In such cases, it is not clear what payment would be made from the consumer's HSA (Hall \& Havighurst, 2005).

\section{Savings plans}

The medical savings account model is most conceptually attractive when funds to pay for medical expenses under the high-deductible plan are readily available within a segregated savings account. Without such an account, policy-holders may fail to use medical services that they do value at full cost because they do not have liquid funds available.

The tax incentives that promote the use of high-deductible health plans coupled with savings accounts in the United States encourage, but do not compel, policy-holders (or their employers) to make contributions to their savings accounts. The tax advantages make fully funding accounts economically attractive, but, in practice, other, similar, tax-favoured savings vehicles, such as retirement accounts, are often underfunded (Burman, Gale \& Hall, 2004).

Contributions to plans may be made by employees, employers or both. In calendar year 2015, over half of employers who offered HSAs made no contribution to their employees' savings plans. Among those who did make contributions, the average contribution to a single plan 
was about US $\$ 1000$, about half the size of the deductibles in these plans (Kaiser Family Foundation and Health Research and Educational Trust, 2016). One study of the earlier medical savings accounts demonstration project found that about two thirds of account holders saved money in their accounts from one year to the next (Minicozzi, 2006).

The extent of under-saving in HSAs is likely to depend on the form they take. If they are offered as a voluntary option, with the taxexempt savings provision as the main inducement for participation, they are likely to attract participants who wish to exploit the tax-free savings component. Conversely, if they are offered as the only option to lower-income workers for whom tax-free saving is not an important consideration, by employers who make a modest or no contribution to the HSA, underfunding of HSAs may be a serious problem, leading to under-utilization of valued care. A recent study found that highincome and older tax filers both established HSAs and fully funded their HSAs at least four times as often as did low-income and younger filers (Helmchen et al., 2015).

\section{Market structure}

The origins of the medical savings account movement were in small to mid-size health insurance plans, such as Golden Rule, and venturecapital-funded entrepreneurial consumer-directed models. Most of these pioneering firms have now been acquired by large commercial insurers, who can offer HSAs in conjunction with other types of insurance products. Anthem, a for-profit insurer formed through the conversion of several non-profit Blue Cross plans, which is among the leading private insurers in market share, bought a venture-capital funded consumerdriven pioneer, Lumenos, in 2005 (Glabman, 2006). UnitedHealth, another of the largest commercial insurers, acquired Golden Rule in 2003 and another consumer-driven firm, Definity, in 2004. Other large insurers have developed their own HSA products.

The medical savings account model requires health insurance to be paired with a distinctly different product, the tax-favoured savings account that accompanies the requisite high-deductible plan. Some insurers have paired up with financial services corporations, which have expertise in operating tax-favoured retirement savings accounts, to manage the new HSAs. Other insurers have chartered their own banks to operate the accounts (Dash, 2006). 


\section{Participation}

In 2015, the total number of Americans enrolled in health insurance plans with deductibles above the HSA threshold (see footnote 285) was about 40 million. Of these, over a third had a health saving account (Cohen \& Martinez, 2015). People may purchase qualified highdeductible health plans and open HSAs either through their employers or in the nongroup market. In the employer market, employers may elect to offer only HSA-qualified plans, or they may offer a choice of plans, including one or more HSA-qualified high-deductible plans.

The nongroup insurance market in the United States had been small, heavily regulated and, until the introduction of tax-exempt HSAs, not subsidized at all. Coverage offered in this market was (and continues to be) less generous than typical employer-based coverage. Many enrollees in this market already had health coverage that incorporated deductibles and cost sharing exceeding the HSA minima, and for them the HSA legislation was an unmitigated boon because it provided a new tax-exempt savings vehicle to accompany their existing health plans. For this reason, much of the early enrolment in HSA plans came from the nongroup market. Passage of the health reform law significantly increased the level of regulation and standardization in the nongroup market, both for those participating in the health care marketplaces and those buying coverage outside them. The least generous plans currently offered (Bronze plans) in the nongroup market are HSA-eligible. As of 2015, about 2 million nongroup enrollees hold HSA-qualified high-deductible health plans (America's Health Insurance Plans, 2015).

As in the nongroup market, one easy source of new HSA enrolment was in large firms that had always offered a high-deductible, indemnity insurance option. In 2003, immediately before the introduction of HSAs, $5 \%$ of American private sector employees worked for firms that offered at least one high-deductible health insurance plan, including $17 \%$ of workers in establishments with 5000 or more employees. Building from this base, about a quarter of all firms now offer an HSA-eligible health plan (Kaiser Family Foundation and Health Research and Educational Trust, 2016).

In settings where employers offer a choice between HSA-qualified plans and other forms of insurance, the share of workers choosing HSAs depends on the required employee premium contributions to the various plans, the nature of plans offered and the extent to which 
the employer contributes to the HSA. On average, the percentage of workers choosing these plans has increased from $2 \%$ in 2006 to $19 \%$ in 2016 (Kaiser Family Foundation and Health Research and Educational Trust, 2016). Many small employers offer only a single type of plan, but several very large firms have also chosen to offer only an HSA-qualified high-deductible option (Glabman, 2006).

\section{Performance}

Future growth in HSAs in the voluntary, private insurance market will depend on the performance of existing plans with respect to cost, outcomes and consumer satisfaction. Here we describe what is known about performance to date.

\section{Costs}

The effects of medical savings account plans on spending depend partly on whether these plans are voluntarily selected or imposed on all market participants. Simulation studies based on the RAND health insurance experiment indicate that moving all Americans from the typical preferred-provider organization plan to an HSA-qualified plan with a savings account could reduce health care spending by about 5-15\% (Baicker, Dow \& Wolfson, 2006; Buntin et al., 2006; Haviland et al., 2012).

If medical savings account participation is voluntary, however, the effect of the high-deductible plan/HSA option will depend on the characteristics of those who select the plans and the nature of the plans that these participants would have held in the absence of this new option. For example, to the extent that early enrollees in HSA plans were drawn primarily from holders of high-deductible plans in the nongroup and large-group markets, the new tax-exempt savings option would not reduce costs and might even lead to cost increases (as cost-sharing payments would now be tax favoured) (Remler \& Glied, 2006).

Studies find that prepayment premiums in HSA-qualified highdeductible health plans are generally lower than in other insurance plans (Claxton et al., 2005, 2006, 2015). This finding is not unexpected, as the lower coverage levels of qualified plans both shift costs from premiums to plan participants and discourage the use of services. 
Most studies of HSA adopters have found that HSA-qualified plans lead to lower average health care costs than other plans, but the nature and magnitude of the estimated effects are critically dependent on what components of spending the studies measure, what the comparison group is, and how well the studies control for the characteristics of people who choose to participate in these plans (Buntin et al., 2006). Many studies conducted by the industry, for example, measure only effects on premiums, ignoring the increases in consumer spending that follow from shifting expenses from premiums to deductibles. Many studies fail to control for selection. Well-controlled studies of early HSA adopters have found only modest effects on total spending when firms switched from standard preferred-provider organization plans to HSA-eligible plans (Parente, Feldman \& Christianson, 2004; Feldman, Parente \& Christianson, 2007). A more recent, well-designed study found that in one large self-insured firm, spending was reduced by $12-14 \%$ after switching from an insurance plan that provided free health care to a high-deductible health plan (Brot-Goldberg et al., 2015).

\section{Health care utilization and outcomes}

A perpetual concern about high-deductible plans, including those associated with HSAs, is that they will lead to reductions in the use of appropriate care, particularly by those with low incomes and by the chronically ill, and therefore lead to worse health outcomes. The RAND health insurance experiment found that differences in cost sharing did not affect the health of most people, but that the health status of some low-income people was compromised by assignment to high cost-sharing plans (Feldstein, 2006). Current versions of HSA-qualified plans, however, differ from the RAND experiment plans in that they provide first-dollar coverage for preventive care, which may mitigate the potential effects of high cost sharing on use of these services.

The existing literature on the effect of HSAs on health utilization shows mixed results (Buntin et al., 2006; Charlton et al., 2011; Reed et al., 2012). Some studies of HSA participants find that their use of preventive services is maintained or even improves, relative to those in traditional plans (Agrawal et al., 2005; Charlton et al., 2011). Other studies find that those in high-deductible plans are more likely to avoid, skip or delay receipt of needed health care (Fronstin \& Collins, 2005; Buntin et al., 2006; Reed et al., 2012). A few studies have found that 
high-deductible plan participants with chronic conditions are more likely than others to follow the appropriate treatment regimen, but these studies did not control for the characteristics of people with chronic conditions who choose to enrol in HSAs (Agrawal et al., 2005). A recent study by Brot-Goldberg et al. (2015) finds reductions in both potentially valuable care (for example, preventive services) and potentially wasteful care (for example, imaging services). Little is known about how HSAqualified high-deductible health plans will affect outcomes. Overall, it appears unlikely that participating in high-deductible plans with taxfavoured HSAs will harm the health of most of those who voluntarily choose them, but the evidence to date does not rule out problems for low-income participants.

\section{Satisfaction}

The final dimension of performance that seems likely to influence the diffusion of medical savings account-style plans in the voluntary private health insurance market is satisfaction. The rhetoric surrounding these plans has emphasized the role of participants as consumers and an important factor in their development has been consumer dissatisfaction with restrictions in managed care.

Perhaps unsurprisingly, the most consistent finding about HSA-style plans to date has been that satisfaction is generally lower among people with these plans than among those with traditional coverage. Fewer than half of participants in the new plans report that they are as satisfied with their current plan as they had been with previous coverage, although this group may be dominated by workers whose employers offered only HSA plans (Agrawal et al., 2005; Fronstin \& Collins, 2005; Employee Benefit Research Institute, 2013).

Although much of the dissatisfaction is undoubtedly due to the increased cost sharing, studies have also found that many enrollees are not satisfied with the information available to help them make medical decisions. Plan participants report that they do not have enough information about the prices doctors charge to make sensible costconscious choices. Many do not trust information on provider quality provided by their insurance plan and seek information from alternative sources (Agrawal et al., 2005). Information provided is often either too aggregated - describing average costs in a market - or insufficiently aggregated - describing costs for subcomponents of care rather than for 
an episode of care - to be useful in consumer decision-making (Reden \& Anders Ltd, 2005; Rosenthal, Hsuan \& Milstein, 2005; Sinaiko, Mehrotra \& Sood, 2016). Information on hospital quality and on pharmaceutical options is more readily available than information on physician quality and cost (Regopoulos et al., 2006). Recent research, however, suggests that even when good information is provided, few members make effective use of it (Brot-Goldberg et al., 2015).

\section{The effect of medical savings account-style plans on the US health system}

The tax-favoured medical savings account model in the US health system has grown over the past decade. HSA-style plans may continue to grow as employers seek lower costs and consumers become more comfortable with the health care decision-making that these plans demand. That outcome has potentially substantial ramifications for the entire system along three dimensions: risk pooling; vertical equity; and consumer choice.

\section{Market segmentation and risk pooling}

The HSA-qualified plans are usually offered as one among several health insurance options. Allowing people to choose these plans can have consequences for the cost of other plans, if HSA-qualified plan enrollees are systematically different in their health care utilization patterns from enrollees in other plans.

Several characteristics of HSA-qualified plans suggest that they attract a distinct group of enrollees. The opportunity to save tax-free through the HSA vehicle is only valuable for those who expect to have funds remaining after paying for their uncovered medical expenses. This feature makes the HSA model more attractive to younger, healthier people than to older, sicker ones. Conversely, people who have health conditions that lead them to spend substantial sums out of pocket each year may find the opportunity to pay for care using pre-tax dollars valuable. To the extent that HSA-qualified plans allow more freedom of choice of provider than conventional plans (this is not always the case), they may also be popular among those with health conditions that benefit from highly specialized care. Studies of enrollees in high-deductible plans generally find that they are somewhat healthier and younger than 
average, but the pattern is not uniform and, in some contexts, enrollees are more likely to be drawn from middle-aged than younger cohorts (Buntin et al., 2006; Greene et al., 2006; Minicozzi, 2006; America's Health Insurance Plans, 2015).

There is undoubtedly a potential for high-deductible plans to promote risk fragmentation. Most employers do not risk-adjust health insurance premiums and concerns that high-deductible plans will skim off the healthiest members of a group and drive overall costs up may be one impediment to their adoption. The tax treatment of employer-sponsored health insurance favours more costly plans, such as those preferred by sicker people. By undoing the effects of existing tax policy, the HSA tax exemption may drive up relative costs for this sicker group. Although the potential for risk fragmentation due to HSAs is real, the magnitude of this effect remains uncertain.

\section{Equity}

The tax exemption for HSA savings is greatest for those in the highest marginal tax brackets and, within this group, for those with the greatest propensity to save. Both features make this benefit most valuable to those with the highest incomes and assets. As noted before, a recent study found that high-income and older tax filers both established HSAs and fully funded them much more frequently than did low-income and younger filers (Helmchen et al., 2015). The tax exemption for HSA contributions also provides a small subsidy for health insurance to those purchasing coverage in the nongroup market, including employed people who are not offered or choose not to take-up employer-sponsored coverage. This subsidy, however, is too small to induce much shifting from the group to the nongroup market.

In its structure, the subsidy offered through the tax exemption for HSAs provides little benefit for most uninsured and low-income people in the United States. About half of uninsured adults do not face any income tax liability, so any plan promoting health insurance through tax exemptions or deductions would not benefit them much. Most uninsured adults who face tax liability are in very low tax brackets and very few have savings, so HSAs are not an attractive option for this group (Glied \& Remler, 2005). Moreover, high-deductible plans combined with HSAs may not provide much value to low-income people, who are unlikely to keep sufficient funds in their HSAs to pay for their medical expenses 
and often have limited disposable income outside these dedicated savings vehicles. Given the choice between contributing towards the premium of an HSA-qualified plan and going without coverage altogether, some lower-income people may prefer to remain uninsured (Glied, 2003b).

Although the promotion of HSA plans does nothing to promote vertical equity in the system, it does not make the system much more regressive, within the context of existing health insurance tax policy. The effect of the HSA tax exemption is largely to counterbalance the equally regressive impact of the existing favourable tax treatment of employer-sponsored health insurance (Cannon, 2006). The Affordable Care Act's high-cost plan tax, known as the Cadillac Tax, which is now scheduled to take effect in 2020 , should have a more progressive impact on health insurance tax policy. Designed to maximize revenue and minimize coverage disruptions, this is a $40 \%$ excise tax on employer plans with high premiums, including those that are HSA-qualified. Because high earners benefit most from HSAs, the high-cost plan tax should help mitigate the regressive effect of favourable tax treatment (Glied \& Striar, 2016).

\section{Consumer choice}

Advocates of medical savings account plans in the United States see the empowering of consumer decision-making as one of their most important benefits. A subgroup of Americans is deeply sceptical that any outside authority - whether the medical profession, a private insurer or the government - will make appropriate trade-offs between the cost and quality of medical care. Sceptics recognize that, given the astronomical costs of catastrophic care, insurance is inevitable, but they wish coverage to take a form that allows them as active a part as possible in making decisions about their own health care.

The HSA model is clearly attractive to members of this group. Enrollees in HSA-qualified plans are substantially more likely to ask about health care costs, to independently identify treatment options and to select among treatments than enrollees in conventional insurance plans (Agrawal et al., 2005; Fronstin \& Collins, 2005). They are more educated and more comfortable with information technology. Allowing a choice of an HSA-model plan permits people with these authority-challenging preferences to escape the limitations of conventional insurance allocation. To the extent that this subgroup exhibits preferences on other aspects of medical care that differ from those of 
conventional insurance enrollees, their departure from the pool has little cost. To the extent, however, that this vocal subgroup provides a constraint on quality-reducing cost-cutting in employer, insurer or government behaviour within conventional health plans, their exit to the HSA market may generate a reduction in the overall quality of the health system.

\section{Conclusions}

Forty years since the idea of HSAs was first introduced, these accounts have become a routine feature of health insurance debates in the United States. The provision of tax-exempt status to these accounts through the passage of the 2003 Medicare Prescription Drug, Improvement and Modernization Act has effectively entrenched them in the landscape, and HSAs have become a growing feature of the health insurance market.

Developments to date suggest that the HSA market, as it evolves, is not likely to lead to the crises feared by opponents. Plans currently on the market must offer access to preventive care at no charge to the beneficiary and some also exempt medications for the management of chronic illness from the deductible. Enrolment in HSA plans has not been associated with deteriorations in health status (although this might change if enrolment shifts to lower-income groups), nor has it led to significantly increased fragmentation of the insurance market.

At the same time, HSA plans are far from achieving the potential promised by advocates. HSA enrollees do not have adequate information with which to weigh costs and quality. They typically fail to maintain sufficient reserves in their savings accounts. Most report that they are less satisfied with their plans than they had been with previous coverage. Most HSA plans continue to contract with physicians and to review utilization above the deductible, so enrollees have not been freed of the constraints imposed by managed care. Although enrolment will probably continue to grow, it seems unlikely that the HSA model will solve the problems of cost, access and quality that plague the US health insurance market.

\section{References}

Agency for Healthcare Research and Quality (2015). Medical expenditure panel survey: https://meps.ahrq.gov/data_stats/summ_tables/insr/national/ series_1/2015/tia2a.pdf; accessed on 07/10/2016. 
Agrawal V et al. (2005). Consumer-directed health plan report - early evidence is promising: www.mckinsey.com/client_service/public_sector/ people/ /media/a4a25ce45a1344c8bf8b0c1eddbcd1c2.ashx. Accessed on 07/10/2016.

America's Health Insurance Plans (2015). 2015 census of health savings account - high deductible health plans: https://ahip.org/wp-content/ uploads/2015/11/HSA_Report.pdf; accessed on 07/10/2016.

Andrews M (2014). States experiment with health savings accounts for Medicaid. National Public Radio (NPR): www.npr.org/sections/healthshots/2014/07/22/333745570/states-experiment-with-health-savingsaccounts-for-medicaid; accessed on 07/10/2016.

Baicker K, Dow W, Wolfson J (2006). Health savings accounts: implications for health spending. National Tax Journal, 59(3):463-75.

Blendon R et al. (1998). Understanding the managed care backlash. Health Affairs, 17(4):80-94.

Bloche G, Studdert D (2004). A quiet revolution: law as an agent of health system change. Health Affairs, 23(2):29-42.

Blumenthal D (2006). Employer-sponsored health insurance in the United States - origins and implication. New England Journal of Medicine, 355(1):82-8.

Bogetic Z, Heffley D (2007). Reforming health care: a case for stay-well health insurance. Policy Research Working Paper Series No. 1181. Washington DC, World Bank.

Brodie M, Brady L, Altman D (1997). Media coverage of managed care: is there a negative bias? Health Affairs, 17(1):9-25.

Brot-Goldberg $\mathrm{Z}$ et al. (2015). What does a deductible do? The impact of costsharing on health care prices, quantities, and spending dynamics. Working paper 21632: www.nber.org/papers/w21632; accessed on 07/10/2016.

Bunce V (2001). Medical savings accounts: progress and problems under HIPAA: http://object.cato.org/sites/cato.org/files/pubs/pdf/pa411.pdf; accessed on 07/10/2016.

Buntin MB et al. (2006). Consumer-directed health care: early evidence about effects on cost and quality. Health Affairs, 25(6):W516-30.

Burman L, Gale W, Hall M (2004). Distributional effects of defined contribution plans and individual retirement arrangements. National Tax Journal, 57(3):671-701.

Cannon M (2006). Health savings accounts: do the critics have a point? Policy Analysis No. 569. Washington DC, Cato Institute.

Centers for Medicare and Medicaid Services (2012). Your guide to Medicare Medical Savings Account (MSA) plans: www.medicare.gov/pubs/pdf/11206 .pdf; accessed on 07/10/2016. 
Charlton ME et al. (2011). Effects of health savings account-eligible plans on utilization and expenditures. The American Journal of Managed Care 17(1):79-86.

Claxton G et al. (2005). What high-deductible plans look like: findings from a National Survey of Employers, 2005: http://content.healthaffairs.org/cgi/ content/full/hlthaff.w5.434/DC1; accessed on 08/08/2007.

Claxton $G$ et al. (2006). Health benefits in 2006: premium increases moderate, enrollment in consumer-directed health plans remains modest. Health Affairs, Web exclusive (5 August).

Claxton G et al. (2015). Health benefits in 2015: stable trends in the employer market. Health Affairs, 34(10):1779-88.

Cogan J, Hubbard G, Kessler D (2005). Healthy, wealthy, and wise. Washington DC, AEI Press/Hoover Institution.

Cohen RA, Martinez ME (2015). Health insurance coverage: early release of estimates from the National Health Interview Survey, January-March 2015. National Center for Health Statistics: www.cdc.gov/nchs/data/nhis/ earlyrelease/insur201508.pdf; accessed on 15/12/2016.

Dash E (2006). Health savings accounts attract Wall Street. New York Times 27 January.

Dolan R (2016). Health policy brief: High-deductible health plans. Health Affairs: www.healthaffairs.org/healthpolicybriefs/brief.php?brief_id=152; accessed on 07/10/2016.

Dotson K (2006a). HSAs and preventive care. Journal of Deferred Compensation, 11(2):3-8.

Dotson K (2006b). Prescription drug coverage in light of consumerism initiatives. Journal of Deferred Compensation, 11(2):9-15.

Dreyfuss R, Stone P (1996). Medikill: www.motherjones.com/news/ feature/1996/01/medikill.html; accessed on 07/10/2016.

Employee Benefit Research Institute (2013). Notes: www.shrm.org/ ResourcesAndTools/hr-topics/benefits/Documents/EBRI_Notes_08_Aug13_RetPart-CEHCS1.pdf; accessed on 07/10/2016.

Federal Register (2016). Patient Protection and Affordable Care Act; HHS notice of benefit and payment parameters for 2017.

Feldman R, Dowd B (1991). A new estimate of the welfare loss of excess health insurance. American Economic Review, 81(1):297-301.

Feldman R, Parente S, Christianson J (2007). Consumer directed health plans: new evidence on cost and utilization. Inquiry, 44(1):26-42.

Feldstein M (1973). The welfare loss of excess health insurance. Journal of Political Economy, 81(2):251-80.

Feldstein M (2006). Balancing the goals of health care provision and financing. Health Affairs, 25(6):1603-11. 
Fronstin P, Collins SR (2005). Early experience with high-deductible and consumer-driven health plans: findings from the EBRI/Commonwealth Fund Consumerism in Health Care Survey. New York, Commonwealth Fund.

Glabman M (2006). Taking the pulse of consumer-driven health plans. Physician Executive, 32(5):CS-259.

Glied S (2003a). Health care costs: on the rise again. Journal of Economic Perspectives, 17(2):125-48.

Glied S (2003b). Health insurance expansions and the content of coverage: is something better than nothing? Forum for Health Economics and Policy, 6 (Frontiers in Health Policy Research): Article 4.

Glied S, Remler D (2005). The effect of health savings accounts on health insurance coverage. New York, The Commonwealth Fund.

Glied S, Striar A (2016). Looking under the hood of the Cadillac Tax. Washington, DC, The Commonwealth Fund.

Gratzer D (2005). What ails heath care? Public Interest, 159:109-24.

Greene J et al. (2006). Which consumers are ready for consumer-directed health plans? Journal of Consumer Policy, 29(3):247-62.

Grudzien L (2006). HRAs or HSAs: how does an employer decide? Journal of Deferred Compensation, 11(2):27-47.

Hall M, Havighurst C (2005). Reviving managed care with health savings accounts. Health Affairs, 24(6):1490-500.

Haviland AM et al. (2012). Growth of consumer-directed health plans to onehalf of all employer-sponsored insurance could save $\$ 57$ billion annually. Health Affairs, 31(5):1009-15.

Heffley D, Miceli T (1998). The economics of incentive-based health care plans. Journal of Risk and Insurance, 65(3):445-65.

Helmchen L et al. (2015). Health savings accounts: Growth concentrated among high-income households and large employers. Health Affairs, 34(9):1594-8.

Hixson J, Worthington P (1978). Alternative prepayment finance for hospital services. Inquiry, 15(3).

Internal Revenue Service (2016). Rev. Proc. 2016-28: www.irs.gov/pub/irsdrop/rp-16-28.pdf; accessed on 07/10/2016.

Internal Revenue Service (2017). Health Savings Accounts and Other Tax-Favored Health Plans. Washington DC, Internal Revenue Service Department of the Treasury.

Jack W, Sheiner L (1997). Welfare improving health expenditure subsidies. American Economic Review, 87(1):206-21.

Joint Committee on Taxation (2006). Technical explanation of H.R. 6408, the 'Tax Relief and Health Care Act of 2006' as introduced in the House on December 7, 2006: www.finance.senate.gov/imo/media/doc/prg121206 .pdf; accessed on 07/10/2016. 
Jost T, Hall M (2006). The role of state regulation in consumer-driven health care. American Journal of Law \& Medicine, 31(4):395-418.

Jost T, Hall MA (2012). Self-insurance for small employers under the Affordable Care Act: federal and state regulatory options. New York University Annual Survey of American Law, 68:539.

Kaiser Family Foundation (2013). Summary of the Affordable Care Act; www.kff.org/health-reform/fact-sheet/summary-of-the-affordable-care-act/; accessed on 20/06/2017.

Kaiser Family Foundation and Health Research and Educational Trust (2015). 2015 employer health benefits survey: http://files.kff.org/attachment/report2015-employer-health-benefits-survey; accessed on 20/06/2017.

Kaiser Family Foundation and Health Research and Educational Trust (2016). 2016 employer health benefits survey: http://kff.org/health-costs/ report/2016-employer-health-benefits-survey/; accessed on 07/10/2016.

Kaiser Permanente (2004). New Kaiser Permanente health plans and health savings accounts (HSA) offer increased access and choice: https://share .kaiserpermanente.org/article/new-kaiser-permanente-health-plans-andhealth-savings-accounts-hsa-offer-increased-access-and-choice/; accessed on $07 / 10 / 2016$.

Kaiser Permanente (2016). Kaiser Permanente: Bronze 60 HSA HMO: http:// info.kaiserpermanente.org/healthplans/california/individual/pdfs/2016-ONExchange/PLNSBC_CAL_800222_9000_20160101_20120501_en.pdf; accessed on 15/12/2017.

Manning WG, Marquis MS (1996). Health insurance: the tradeoff between risk pooling and moral hazard. Journal of Health Economics, 15(5):609-39.

Minicozzi A (2006). Medical savings accounts: what story do the data tell? Health Affairs, 25(1) 256-67.

Moran A, Farmer G (2007). Health savings accounts: will new legislative changes increase their use? Employee Relations Law Journal, 33(1):87-99.

Musumeci M, Rudowitz R (2015). The ACA and Medicaid Expansion Waivers. Kaiser Family Foundation Issue Brief: http://kff.org/reportsection/the-aca-and-medicaid-expansion-waivers-issue-brief/; accessed 09/10/2016.

Newhouse J (2004). Consumer-directed health plans and the RAND Health Insurance Experiment. Health Affairs, 23(6):107-13.

Parente S, Feldman R, Christianson J (2004). Evaluation of the effect of a consumer-driven health plan on medical care expenditures and utilization. Health Services Research, 39(4 part 2):1189-210.

Pauly M (1968). The economics of moral hazard: comment. American Economic Review, 58(3 Part 1):531-7.

Pauly M (1986). Taxation, health insurance, and market failure in the medical economy. Journal of Economic Literature, 24(2):629-75. 
Pear R (1996). G.O.P. plan would profit insurer with ties to party. New York Times 14 April.

Reden \& Anders Ltd (2005). Consumer directed insurance products: survey results. Internal company report Minneapolis, MN, Reden \& Anders Ltd.

Reed ME et al. (2012). In consumer-directed health plans, a majority of patients were unaware of free or low-cost preventive care. Health Affairs, 31(12):2641-8.

Regopoulos L et al. (2006). Consumer-directed health insurance products: local-market perspectives. Health Affairs, 25(3):766-73.

Reinhardt U (1998). Quality in consumer-driven health systems. International Journal for Quality in Health Care, 10(5):385-94.

Remler D, Glied S (2006). How much more cost sharing will health savings accounts bring? HSAs don't appear to be living up to their reputation for increasing consumers' cost sharing. Health Affairs, 25(4):1070-8.

Robinson J (2005). Consumer-directed health insurance: the next generation, Health Affairs Web exclusive (13 December):W583-W590.

Rosenthal M, Hsuan C, Milstein A (2005). A report card on the Freshman class of consumer-directed health plans. Health Affairs, 24(6):1592-600.

Scheffler R, Felton M (2006). Consumer-driven health plans: new developments and the long road ahead. Business Economics, 41(3):44-8.

Sinaiko AD, Mehrotra A, Sood N (2016). Cost-sharing obligations, highdeductible health plan growth, and shopping for health care: enrollees with skin in the game. JAMA Internal Medicine, 176(3):395-7. 